\title{
Engineering and the Politics of Commensuration in the Mining and Petroleum Industries
}

\author{
JESSICA M. SMITH \\ COLORADO SCHOOL OF MINES \\ NICOLE M. SMITH \\ COLORADO SCHOOL OF MINES
}

\begin{abstract}
Engineers and applied scientists form the backbone of the mining and petroleum industries, yet rarely figure in social science accounts of natural resource extraction. This article begins to fill that gap by ethnographically exploring how community conflicts have prompted engineers and applied scientists working in these industries to reconsider the relationship between the surface and subsurface dimensions of their work. To make social concerns on the surface matter to how drilling and extraction would happen, they tried to make these two domains legible to one another. Using mapping and modeling, they created new techniques for making "social" concerns visible and actionable by field operators, even as they expressed reservations about unduly flattening the inherent complexity of human thought, action, and emotion in the process. While these practices opened space for other engineers and applied scientists to incorporate the concerns of nearby residents into their plans and practices, they also raised questions about the appropriateness of commensuration, or the process of translation through which things and values are made comparable.
\end{abstract}

\section{Keywords}

mining; fracking; engineers; controversies; corporate social responsibility

\section{Introduction}

Engineers and applied scientists make possible industrial scale resource production, from the initial sampling and modeling used to map reserves to the design of techniques and technologies for reclamation. Furthermore, the questions that lie at the heart of conflicts between companies and local communities- those surrounding air and water pollution, noise, dust, the location and scale of infrastructure, monitoring programs, and plans for mitigation or even resettlement-all directly engage engineers and applied scientists. Yet these actors are strikingly absent in an

Jessica M. Smith, Email: jmsmith@mines.edu . Nicole M. Smith, Email: nmsmith@mines.edu

Copyright (c) 2018 (Jessica M. Smith and Nicole M. Smith). Licensed under the Creative Commons Attribution Noncommercial No Derivatives (by-nc-nd). Available at estsjournal.org. 
otherwise substantial and growing social science literature on resource extraction. Anthropologists, for instance, have long investigated the interface between mining companies and the people involved with or affected by their activities, such as workers and nearby populations (e.g. Nash 1979; Powdermaker 1962). More recently, they have analyzed the escalating conflicts between companies and their critics, grounding their work in the groups and social movements opposed to extractive activity (e.g. Jalbert et al. 2017; Kirsch 2006, 2014; McNeil 2011; Sawyer 2004; Willow et al. 2014). Engineers and applied scientists rarely feature as actors in these accounts, with a few notable exceptions that engage anthropology along with STS (e.g. Kneas 2016; Li 2015). In STS, questions of how science and expertise come to matter in these conflicts are most often taken up in relation to citizen science contesting industry (e.g. Jalbert and Kinchy 2015, Kinchy 2017). Taking inspiration from the STS impetus to critically question the knowledge, expertise and power underlying appeals to science, this article builds on these literatures by ethnographically exploring how questions of social responsibility shape the work of engineers and applied scientists inside of mining, oil and gas companies.

In this article, we argue that community conflicts present engineers and applied scientists with a direct challenge to one of the central organizing themes of their professions: the "ideology of depoliticization" (Cech 2013). As theorized by Erin Cech, the ideology of depoliticization refers to the "belief that engineering work can and should be disconnected from 'social' and 'political' concerns because such considerations may bias otherwise 'pure' engineering practice" (Cech 2013: 48). It provides one instance of a much larger phenomenon in which fundamentally political problems are reduced to technical ones, restricted to the hands of experts and technocrats (e.g. Li 2007; Ferguson 1994). Yet in our research we found that community conflicts did not inspire practicing engineers and applied scientists to shore up and take shelter within the ideology of depoliticization and the social/technical dualism on which it depends, as scholars have noted for other industrial conflicts (e.g. Ottinger 2013). Instead, these conflicts prompted them to consider the subsurface and surface as interlinked, mutually dependent and, in some cases, mutually constitutive. This contrasted commonsense understanding in their fields, which holds these two domains as distinct, animated by conflicting logics (irrational human thought, action, and emotion on the surface versus scientific principles underground), and therefore requiring different tools and perceptual techniques.

For all of the engineers and applied scientists we met, community conflicts generated deep concern over how to make the surface and subsurface legible and potentially responsive to one another. Moving between these two domains, we argue, opened up "new points for opposition or engagement on the part of the people who might be affected by... corporate actions" (Mathews and Barnes 2016: 10). Mapping and modeling came to figure centrally in how engineers and applied scientists attempted to translate-and debated the merits of translatingthose two domains to their coworkers. They created new techniques for making "social" concerns visible and actionable by field operators, even as they expressed reservations about unduly flattening the inherent complexity of human thought, action, and emotion in the process.

The ethnographic material we present draws on two years of research primarily with engineers and applied scientists practicing in the mining, oil and gas industries. During this time, 
we conducted over sixty interviews with individuals who held various positions in these industries, also including landmen, legal professionals and social responsibility practitioners. Engineers comprised the bulk of the participants, representing more than $75 \%$ of the study population, and they ranged from recent graduates in their first year of professional work to CEOs on the cusp of retirement. They worked for a variety of companies, from small, locally based operations with less than ten employees to large multi-national corporations with a global portfolio and workforce. Some worked for consulting companies that provided technical and regulatory expertise to mining and oil and gas companies. About a third of our interviewees were women, which is a slight over-representation given that women comprise just over 10 percent of the engineering workforce and about 20 percent of recent engineering graduates. Most but not all of our interviewees either lived or worked in Colorado, some after significant experience working in other parts of the U.S. or around the world.

While we identified differences among our interviewees according to age, gender, educational background, and industrial experience, all of them shared stories of coming to recognize the importance of social responsibility, not just for their own sense of "doing the right thing," but also for the survival of their industries. In this article, we focus particularly on engineers and applied scientists working in Colorado's contentious oil and gas industry. In the past decade, the advent of horizontal drilling and hydraulic fracturing technologies has spurred a boom in oil and gas production from shale formations, bringing energy development into a "collision course" with the Denver metro's burgeoning suburbs (Svaldi 2017). Calls for bans and moratoriums on fracking have become a central feature of public debate, with five communities instituting them before the state supreme court ruled two of them to be unconstitutional.

Our research revealed that these community conflicts shaped and were shaped by the practice of engineering. We found that reservoir engineers make decisions about which wells to plug, not just based on the economic value of the remaining resource, but on the social and economic value of landowner attitudes and acceptance of their operations. Well planners factor in the location of hospitals, schools and major roads as they recommend locations for new drilling sites. Even the engineers who most closely embody the stereotype of a number cruncher seeking to protect the financial bottom line recognized the financial value of community acceptance.

We begin by laying the theoretical groundwork, showing how a dearth of attention to engineers and applied scientists has hampered scholarly understanding of how natural resources "become" by blackboxing the everyday enactments of corporations. We then turn to our ethnographic data to explore how divisions between the subsurface and surface are produced and partially undone through the everyday working lives of engineers and applied scientists in the oil and gas industry. Next, we explore how some of these actors attempted to translate between those two domains through creative mapping and modeling practices. While these practices opened space for other engineers and applied scientists to incorporate the concerns of nearby residents into their plans and practices, they also raised questions about the appropriateness of what anthropologist Fabiana Li $(2011,2015)$ terms commensuration, or the process of translation through which things and values are made comparable. We conclude by 
considering the possibilities and pitfalls of more socially responsible forms of commensuration for making resource extraction more responsive to the concerns and desires of people living in close proximity to these sites.

\section{Enacting Corporations by Engineering "Natural" Resources}

Materials conventionally referred to as resources, such as oil and gas, actually exist in distributed assemblages of extractive infrastructures (such as pipelines, roads and tanks), everyday practices, entities such as corporations, and discourses of the market, development and nation (Richardson and Weszkalnys 2014). While material characteristics provide affordances that shape the ways in which subsurface materials are understood, assigned value, and extracted, these processes are ultimately political, involving contestations over knowledge, expertise, and power that draw in engineers and scientists (Mathews and Barns 2016; Li 2015; Rolston 2013).

Engineering and applied science are fundamental to the ways in which minerals become resources through the vast infrastructural networks that map, extract, process, transport and use them. The authors of the influential edited volume Subterranean Estates: Life Worlds of Oil and Gas (Appel et al. 2015) chose Pablo Neruda's 1940 "Standard Oil Co." poem to open the book. In the poem, oil comes to be through complex regimes of politics, property and finance, but it is a "pale engineer and a title deed" at the beginning of the journey. Building on Timothy Mitchell's work illustrating how political, social and economic relations are "engineered out of the flows of energy" (2011: 5), Hannah Appel and her colleagues write, "Engineering in this capacious sense is never just a reflection of a political or economic order developed de novo by oil but the outcome of complex accommodations, compromises, complicities, oppositions, and violence" (2015: 18). In the book we learn that the work of engineers contributes to the "modular" functioning of offshore oil production (Appel 2015) and that the purified results of their research and practice appear in the "oil archive" (Barry 2015). Additionally, major energy corporations influenced both the scientific review of the EPA's historic report on hydraulic fracturing and water contamination and university research on the topic through appointing their engineers to review committees and research teams (Wylie 2015).

Yet despite the centrality of engineers and engineering for the oil and gas industries, the 400-page book tells us precious little else about engineers or engineering practices. Other ethnographic research sheds light on the specific logics that shape the thoughts and practices of engineers and applied scientists. Gwen Ottinger's (2013) book Refining Expertise argues that engineers who consider themselves "responsible" nonetheless subvert environmental justice in the context of a controversial petrochemical refinery, since discourses and practices of corporate social responsibility allow those "technical" people to admit mistakes in the "social" realm (chiefly in terms of communication), rather than in the actual "technical" practice of their companies. This leaves intact their own expertise and authority in the management of the primary concerns of nearby residents, including toxic emissions and leaks. Ottinger's analysis shows the ideology of depoliticization at work, enabling engineers and managers to shore up corporate expertise in the face of critique. 
In a similar vein, David Hughes (2017) critiques engineers and applied scientists for enabling the expansion of the oil industry and therefore remaining "complicit" in hastening the "great evil of dumping carbon dioxide into the skies" (2017: 14). Tracing the history of graphical representations of oil in the subsurface, he insightfully reveals a "vernacular science of hydrocarbon uplift" that naturalizes oil extraction (2017: 68): the petroleum geologists imagine their work to be liberating oil's "natural" desire to come to the surface, in contrast to the laborious extractive activities of mining that force minerals to the surface (2017: 65). Hughes identifies moral malfeasance in this practice and their profession more generally, writing, "the petro-geologists among my informants are in the wrong and doing wrong" (2017: 151). He unapologetically admits a "condescending, judgmental tone" (2017: 151) when analyzing his interviewees and fieldwork data, arguing that his perspective is warranted by the grave dangers of climate change.

For Hughes, engineers and applied scientists are primarily motivated by neoliberal logics of contemporary capitalism and the drive for profit. But we should take caution before presenting monolithic portrayals of these professionals as mere conduits for carbon capitalism. The engineering profession is indeed powerful, but it is also fraught with its own internal tensions and contradictions. Fabiana $\operatorname{Li}(2011,2015)$, for example, shows that engineers in Peru who work for major mining companies do privilege the profitability of their corporate employers when planning mines and dealing with community conflicts, especially when they work in management positions. But she also points out that these mining companies employ engineering consultants in order to capitalize on their expertise in a particular area. These engineers are not wholly defined by the interests of capital, and attempt to weave "good practices" into their recommendations to the companies.

Li shows, however, that these engineers frequently find themselves limited in their ability to force a company's hand because of the structural conditions of their work. Because they are limited to particular projects, they rarely get to see the "complete picture," in the words of one of her interviewees. Moreover, they are asked to bring their expertise to bear on questions of how things should be done, not whether they should be done, as one engineer explained: "As consultants, we limit ourselves to the question that is put to us." In that case, "the question was 'How much water is there (in the watershed)?' His role was not to make a judgment on whether that amount was sufficient for the mine's processes, or to determine the mine's possible effects on water quantity for agricultural uses." Another was more direct: "We are engineers, and we are an engineering firm. Our commitment is to the client, and we have to help clients carry out their project. We [cannot] get fundamentalist with environmental themes" (2011: 64). Li's work stands out for bringing these internal contradictions in engineering to the fore of understanding how mining and community conflicts actually unfold.

The institutional location of engineers as corporate employees has facilitated the practice of otherwise critical scholars simplistically equating their interests with their employers. Anna Willow's (2014) research in Ohio, for example, documents the transformations that have accompanied the unconventional energy boom and altered residents' relationships with landscapes that are increasingly understood as untrustable. Yet when industry or company 
personnel refused to be interviewed or were unresponsive to interview requests, she chose to review and code "publicly available statements that addressed social and environmental aspects of corporate sustainability" (2014: 58) in the same manner as the interviews she conducted with residents. Willow suggests that these documents are representative of the views of the people who work for corporations: "Although a range of opinions is certain to exist among corporate employees, the oil and gas industry's general unwillingness to deviate from or complicate public communications suggests that most industry representatives are amenable to having their views represented through these channels" (2014: 58). Her approach may reveal how a team of employees in public relations departments, working under direction from upper management, represents their companies to a public audience, usually understood to be critical if not openly adversarial to their industry, but this should not be mistaken for individuals' thoughts about their employers or the industry in which they work.

Why might such reductive approaches to understanding engineers and engineering be acceptable to scholars in ways that they would otherwise find offensive if applied to the more traditional subjects of our research, such as the communities affected by mining and energy development? In part, the impetus to treat engineers and other corporate actors as vessels of their employers likely stems from a perceived alliance between the engineering profession and the interests of capital. There is some truth behind such a view, as engineers have long struggled for professional autonomy. In the US, the engineering profession developed in a way that transformed engineers from "builders of the system" to "servants of the system" and their corporate employers (Wisnioski 2012). David Noble shows that the advancement of the engineering profession was directly tied to the rise of large corporations in the late $19^{\text {t }}$ century, making the industrial corporation the "habitat of the professional engineer" and giving rise to "confusion and delusion" between business leadership, corporate employees, and their own scientific professional identity (1979: 43, 40). Edwin Layton's foundational The Revolt of the Engineers: Social Responsibility and the American Engineering Profession (1971) chronicles the subordination of the engineering profession to corporations in the first part of the 20" century, concluding, "There can be little doubt that engineers derived substantial benefits from their alliance with business. But there was a danger that in gaining worldly things the engineering profession might have lost its own soul" (Layton 1971: 218).

However much the interests of the engineering profession and individual engineers have been tied to the business interests of their employers, it does not mean that engineers have been turned into corporate automatons, as ethnographic and historical research makes clear. In Li's account, engineers who describe themselves as interested in societal and environmental wellbeing depend on corporations to hire their consulting services, but they maintain a critical stance toward the mine's activities and find ways to work inside its institutional limitations. Reaching back to the 1960s, Matthew Wisnioski (2012) shows that some dissident US engineers articulated more radical arguments calling for engineering to promote societal wellbeing, but that the rhetoric of responsibility they espoused was coopted back by business.

The work of engineers does directly enable the expansion and operation of particular mining and energy companies as well as the industry as a whole. But this does not happen 
without critique, hesitations, and missteps. Critical analyses of capitalism must go beyond attributing the power and authority of corporations to some "inexorable, expanding logic of capital" (Welker 2009: 166) in which the "concrete specificity of the industry itself has receded into a thin portrayal of a revenue-producing machine-a black box with predictable effects" (Appel 2012: 693). While there is political power in ascribing unitary personhood and agency to corporations, such as by holding a particular company legally responsible for negligence, doing so also hampers our ability to understand how and why harms happen. Following Marina Welker, corporations are not monolithic revenue-producing machines, but entities that are "inherently unstable and indeterminate, multiply authored, always in flux, and comprising both material and immaterial parts" (2014: 4). Corporations must therefore be enacted, and this performance can be amateurish, unconvincing or incomplete, depending on the actual people and practices in play (Kneas 2016, n.d.). Multiple and sometimes contradictory ideas and systems are made to "hang together" (Mol 2002) in a corporate form, with competing interests and logics resulting in corporations being enacted to different effects.

Engineers are central to the enactment of corporations, and these actors' own desires and practices do not always neatly conform with those of corporate managers and executives. In the pages that follow, we open up the black box of corporations to consider engineers as social actors in their own right, illuminating the contested politics of how resources "become" as these actors produce and transgress distinctions between the subsurface and surface.

\section{"Two Different Worlds"}

The subsurface and surface are not self-evident, pre-existing domains of thought and practice, but are actively produced by the actors who engage them. In the case of a would-be copper mine in Ecuador, for example, David Kneas (2016) shows that corporate actors produced the subsoil as abundant in order to marshal support for the controversial mine they sought to open. By analyzing the ways in which company employees modified the block modeling and search radius techniques to estimate the potential copper reserves of the site, he shows that resource estimates are not a "thing, but a doing, an ensemble of performative actions that gesture towards the prospect of abundant subsoil copper" (2016: 69). In presentations to nearby residents, however, company representatives downplayed the scale of potential mining activities, emphasizing that they were in an exploratory stage that might not result in large-scale mining. To further garner local support, they constructed the above-ground region as suffering from irresponsible deforestation that only the mining company could halt. This case of the copper deposit-and junior mining firm-that failed to "become" bespeaks broader tensions in how the Ecuadorean subsurface is produced, as Kneas argues in this volume: politicians and geoscientists present conflicting views of the Ecuadorean subsurface as either part of or an exception to an unbroken Andean chain of resource abundance.

Our research suggests that the everyday enactments of companies and actors in the extractive sector actively produce the surface and subsurface as two distinct fields of practice and knowledge. People in the oil and gas business, for example, distinguish between "below ground" 
and "above ground" risks, with the latter encompassing the span of Health, Safety, Security, Environment and Social Responsibility (HSSE-SR). One of our interviewees critiqued the everlengthening acronym for serving as the "bucket" into which technically-trained industry people "threw everything having to do with human beings." These distinctions are institutionally reinforced through reporting chains and work groups: most companies have dedicated community and government relations teams comprised of people with social science backgrounds that report up a different chain of command than do the production, drilling and completion teams that are comprised of petroleum and other engineers and applied scientists.

The majority of our interviewees distinguished the "above ground" and "below ground" personnel and activities of the company as being characterized by different approaches to understanding and solving problems. A geological engineer named Matt exemplified the views of the majority of the engineers and applied scientists we interviewed. "Land people are not very quantitative at all. They negotiate things, and they're working to improve our relationships with surface owners and mineral owners." In contrast, engineers just want to know the "value of a decision." He explained, "We [engineers] know there's a way to quantify this" even when the land people "can't be pinned down... So usually it's the reservoir engineer team at the time sits around and we just decide, we come up with ways to quantify some of those intangibles." Matt also acknowledged, however, that there were limits to this generalization and that he might be "over-quantifying" the "engineer types," saying, "Even amongst my [engineering] coworkers, there's people who just believe in social license as a good thing." But he reinforced the necessity and value of trying to make these quantifications by concluding, "People like myself, I always think there's a dollar figure you can put on everything that you do."

Even engineers who hold a great deal of respect for stakeholder teams emphasize differences between "social" and "technical" work. Ryan's career trajectory was unique; he spent time on the stakeholder relationships team for a major oil and gas operator in Colorado after working as an operations geologist for the same company. In that initial position, he was the "eyes underground" while the field crew was drilling a new well, interpreting the data streaming in from the drill bit to determine what kind of material they were drilling through in order to "geosteer" the drill to the correct location. His job was essential for the entire operation. Missing the correct location for the well would cost the company millions of dollars in a lost investment. While the drilling plans were based on models generated from core samples, there was always a chance that the actual underground would differ since the formation rises and dips and is punctuated with faults. Ryan became adept at determining which kind of rock the crew was drilling based on a stream of numbers that were fed to his computer screen in real time, at the same time as he came to appreciate the expert knowledge of the drillers, since they would often feel when they encountered something unexpected before it appeared on his screen. His passion for the underground was unmistakable, as he talked at length about his love for all things subsurface.

When oil and gas prices slumped in 2016 and drilling activity almost ceased to a halt, he was transferred to the stakeholder engagement team, where he served as the only member with a science and engineering background (though he also enjoyed his liberal arts courses as an 
undergraduate). When discussing his unique career trajectory, he distinguished the subsurface as being "all about numbers, very quantitative and scientific" in comparison with the surface, which is "all qualitative" and requires a lot of listening to stakeholders to understand "exactly what their concern is" in order to address it, as well as to "identify the times you just need to listen." He distinguished a "numerical subsurface" from a "non-numerical" surface. In terms of the data and markers of success that characterized both capacities, his geological work had "clear attributes," whereas he wondered how to measure success in his stakeholder engagement work: How do you measure feelings and thoughts? For him, doing so exceeded the more conventional metrics he used to understand the subsurface calculations.

\section{Commensuration: Numbers and Narratives}

Moving between the subsurface and surface concerns prompted engineers and applied scientists like Matt and Ryan to question how these two domains-socially constructed as distinct if not oppositional—could be made legible and perhaps even responsive to one another. These concerns infused both their own professional practice and the institutional spaces in which "above ground" and "below ground" experts directly engage one another. In response to community conflicts in Colorado, for example, engineering and community relations experts sit in a room together to analyze the opportunities and challenges of new fields, understood not just in their geologic and economic characteristics but also in their social and political ones. "You cannot assess the viability of a new development without understanding who lives there," explained an engineer who had moved into management. "The biggest challenge is not discovering new resources but figuring out how you manage the social component to make sure you can get them out of the ground."

Communicating risks and opportunities from the perspective of different disciplinary expertise involves the practice of what Li $(2011,2015)$ terms commensuration: the process of making entities and values comparable with one another. In her work, she focused on the ways in which scientists and engineers translate a project's impacts into measurable, quantifiable data. Commensuration was central to the work of the Peruvian engineers she studied, as they weighed different pollution mitigation plans or compensated villagers for lost water. "Implicit in this approach," Li argues, "is an attempt to separate the 'technical' work of engineers from 'social' and 'ecological' considerations" (2011: 64). Despite those limitations, the equivalences that are central to their work can be contested by the people affected by it, illuminating "what falls outside of market and rational calculation" and the ways in which these spur "new relations of collaboration and antagonism" (2015: 25). As Li shows, making things like sacred mountains and water sources "incommensurable" is a powerful tool for limiting industry. Her work illustrates how resources like mineral deposits or sacred sites do not simply exist, but become through contested practices of commensuration, to which engineering and applied science are key.

Commensuration was clearly a part of the everyday working lives of the engineers we interviewed. Matt, who had worked his way into management, recounted the complex negotiations at play in his company's decisions to plug wells, taking them out of production, 
often in order to gain a "social" benefit in terms of improved relationships with landowners and communities. "It's also not worth the time, typically, to have a well that bothers a surface owner and doesn't make much value for the company," he said. He described two groups of people involved in those negotiations: the production and reservoir engineers and the landmen, who manage social relationships and negotiate legal rights with landowners. "It's two: people who are interacting directly with the owners versus the people who are in charge of the decision of the value and protecting the value to the company. And so, and they can be at odds, but it's everyone's job is to drive value, so you have to kind of come to agreement at some point." In his mind, those agreements boiled down to putting a dollar value on the relationship. "How many new wells can you drill based off getting rid of this old well?" Here commensuration appears as the expertise of engineers.

A petroleum engineer named Aaron dedicated a substantial part of his career to broadening the ways in which social concerns could be translated to technical teams beyond crude financial calculations. The impetus for his work came from seeing that the below ground people either struggled to integrate or did not desire to integrate information from the stakeholder relations team into their technical work of planning fields, siting specific wells, or coordinating the activities surrounding that well, such as the hours of operation, flow of truck traffic or schedule of deliveries. While working on the stakeholder relationships team, he and his coworkers developed maps and models to serve as visual aids to help their "technical" colleagues make more socially informed and responsive decisions. These included maps of complaint locations; charts showing the time of day/night of calls to their grievance line; charts distinguishing types of calls into their hotline (e.g. complaints versus requests for information); and GIS layers of schools, hospitals, and other key places that should be avoided when siting wells. He explained:

If we went and spoke narrative about someone who couldn't sleep at night, there's nothing that a drilling engineer can do with a narrative... They don't become more efficient drilling a well from narrative. They don't control costs by narrative. Nothing happens in their world in just talking. They have to look at data, analyze it, and then make an action to it. It's the exact same thing. So we didn't have a narrative around the noise of rig activities at night. We showed a graph of complaints and time of day and it said, "The common element in this is you are delivering the steel pipe at 3:00 in the morning. Do we have to do that?" [They would reply] "Well, no. We could deliver it at 3:00 in the afternoon." You could've spun that narrative and it wouldn't have mattered. It wouldn't have sunk in and attached to people. When you showed them the data, and then provided the context, you nailed it. Or if you showed the map exhibit and your rig A over here has these complaints, and rig B has no complaints, here's the proof that it's related to rig A and it's not some other company's rig. It's your rig and it's this specific item.

When Aaron said, "It's the same exact thing," he is referring to his team's ability to turn "narrative" into "data" that can be understood and engaged by people more skilled and comfortable with quantitative information. These tools helped engineers see the patterns and 
common themes in the narratives that the stakeholder team heard day in and day out. By creating graphs and charts, his team was able to carve a space for engineers to change their professional practice in ways that improved stakeholder relationships.

This translation, however, was asymmetrical. For Aaron to bridge the entrenched divide between the technical and social inside of his company, he had to make qualitative data "speak the language" of quantitative representation to allow for alignment of views:

That's the power of those exhibits and that's one of the ways that the technical person can participate in this is to help the socially-oriented, the communications major, the sociologist, convert their world, translate their world into something that the oil and gas operative, technical person, blue collar team member can do something with... The power of a map isn't that all the dots are accounted for. The power of a graph isn't that the trend is up. The power is that all of us who are looking at it have the same conclusion of what is going on. We all agree that those are the sum total of the dots.

One of the reasons this approach is compelling for Aaron and his below ground coworkers is that it helps them identify specific causes of social problems that might otherwise appear irrational, unpredictable or arbitrary, allowing them to formulate solutions that are more likely to result in community acceptance. This approach resonates with root cause analysis, a familiar exercise to engineers and applied scientists accustomed to identifying the causes of events like equipment failure. According to Aaron, "The power for the internal people is to dissect, 'Why did that generate that, and can we be aware of that as we go to plan the next piece, the next step? Can we be better when we plan the next step?'" The idea that there is a discoverable, underlying pattern of community conflicts means that they can be prevented in the future. This is a powerful argument that serves as a safeguard against accusations that would devalue the work of community relations teams such as his own: if conflicts are random, the logic goes, companies should not waste their time investing in preventing them in the first place.

While Aaron achieved a great deal of success with his mapping and modeling techniques, other engineers and applied scientists were wary that creating compelling patterns of "social data" also required smoothing out the inconsistencies and unpredictabilities of human thought and behavior, giving a false impression that "social risks" can be managed in the same way as "technical" ones. In other words, they worried that making above ground risks understandable to their below ground workers could erase the unique expertise required of working with people. Ryan, for example, expressed reservations about translating the "qualitative" concerns of stakeholders into the "quantitative" language preferred by the engineers in his company. When asked if it were possible or valuable to identify patterns in stakeholder perceptions or feelings in ways that were similar to how people did so for the underground, Ryan emphatically insisted that operating in these two very different domains required two very different skill sets. "People aren't numbers," he said. They have "feelings, thoughts, minds. Motives. Emotions." Then he illustrated his point about the unpredictability of people by telling a story about how he and his team were surprised by a neighborhood resident who they guessed was going to be the type that would submit complaints to them and to the 
state, but so far had said nothing. He strongly felt that if representatives of the oil and gas industry engaged social problems in the same way that they approached engineering problems, they would "propagate the problem further" because they would appear to be tone deaf to the actual complexities and sensitivities of working with people. Whereas Aaron emphasized the power of packaging "narrative" data into graphical and numerical forms familiar and digestible to engineers so that they can make decisions that are responsive to community concerns, Ryan worried that such commensuration erases the uncertainties-and their expertise in managing them-inherent in the stakeholder team's work.

Ryan's critique of engineers being intolerant of uncertainties-and therefore a bad fit for stakeholder engagement-was a familiar refrain among some of the applied scientists we interviewed. A geologist named Nicki said that in her experience, the biggest difference between them was that "engineers think very linearly and can't tolerate ambiguity, whereas geologists are willing to admit, and have to admit, that what they are doing is making educated guesses." For her, dealing with the underground raised inherent ambiguities. "There is never a right answer, no way to know for sure. You are observing processes that happen deep in the crust of the earth and that you can't observe directly. You make inferences." She explained that whereas the task of a geologist is to "justify your guess," for engineers, "there is one right answer, and it's gospel." She viewed engineers as unreasonably attached to false senses of certainty belied by her work as a geologist. Like Ryan, she suggested that respect for unpredictability in the subsurface can predispose one to tolerate ambiguity in understanding human relationships.

Negotiating uncertainty is a key component of scientific practice (Barnes 2016). Martin Espig and Kim de Rijke (2016) go even farther, arguing that engineers and applied scientists encounter "an almost omnipresent engagement with limited knowledge, uncertainty, and risk" during the everyday course of their work in coal seam gas development in northeastern Australia (6). The way they encounter and understand risk differs substantially from the ways in which people who live in close proximity to wells do; unlike the residents, engineers have a more abstract and less material, embodied understanding of risk and its social and environmental consequences. Espig and de Rijke raise the concern that if industry professionals treat uncertainties as an integral part of business as usual, it normalizes them.

In making the above ground legible to below ground experts, Aaron and his team are like other modelers and must make compromises, recognizing that the patterns they identify are "approximations of approximations" (O'Reilly 2016: 41). Yet for our interviewees, making visible the inherent constraints, unique biographies, and specific purposes of models (Mathews and Barnes 2016) threatens to delegitimize them in the eyes of their engineering and applied science coworkers, who value data they consider objective. It is no accident that the seduction of objectivity pervades the oil and gas industry, whose management as well as workforce is comprised primarily of engineers and applied scientists. Indeed, presenting necessarily messy and complex operational data as seemingly unambiguous science was a key strategy through which Schlumberger became the world's largest oilfield service company (Bowker 1994). The challenge for Aaron, his team, and their kindred spirits we met boils down to translating qualitative information into legible quantitative forms. To shape the practice of their "below 
ground" coworkers, this translation must be done in a way that borrows from the perspectives and tools familiar to people with a technical background so that it is compelling to them. The lingering question is how to accomplish that translation without simultaneously giving a false sense of certainty, which does not reflect the actual vagaries of human experiences, nor the unique skills and expertise of the people who have dedicated their professional lives to navigating those complexities.

\section{Conclusion}

Engineers play a central role in natural resource development. Their decisions shape both the small details and large contours of how that development happens, from siting wells to selecting the technologies used to drill them. Understanding and intervening into contemporary debates about resource extraction thus requires engaging the engineers and applied scientists who form the backbones of these industries. "Engineers have escaped attention... because they are rarely considered to be distinct and worthy cultural subjects when compared to scientists, intellectuals, or artists" (Wisnioski 2012: 8). Social science research on extraction too often treats engineers as "people without culture" (Rosaldo 1988), despite careful ethnographic and historical attention to the cultural construction of engineers and engineering practice in STS (e.g. Downey 2009; Downey et al. 2007; Downey and Lucena 2005; Lucena 2007, 2009; and the entire peer-reviewed journal Engineering Studies).

While engaged scholars should critique and intervene in the production of harms, the danger rests in presenting a monolithic portrayal of an internally complex field. In the US, the majority of engineers do work for corporations, but that does not mean that their thoughts and practices are subsumed by their employers. Rather than simply serving as empty vessels to be filled with already existing corporate discourses, engineers and their coworkers enact corporations through their everyday practice (Welker 2014). That practice is shot through with tensions among and between different disciplines, institutional teams, and employees.

These tensions were evident in our research in Colorado, where community conflicts prompted engineers to consider how subsurface resource production can be done in a way that is responsive to the concerns of the people most directly impacted by it. Community conflicts challenged each of them to see the technical and social, the quantitative and qualitative, the below ground and above ground as interlinked domains. Yet they expressed different levels of reservation about the practices of commensuration through which they translated between these domains. For Matt, commensuration was a necessary part of his work strategically planning the initiation and retirement of activities, as it made it possible for him to assign a dollar value to a relationship with a landowner. Nicki agreed that erasing the ambiguities through commensuration was part and parcel of engineering. For Aaron, commensuration was a powerful tool to get otherwise unreceptive coworkers to integrate community concerns and desires into the ways in which wells were planned, drilled and managed. Ryan also saw the value of commensuration, but stressed that it was an imperfect strategy for making oil and gas activity responsive to the people it affected. He, more than anyone, critiqued the asymmetries of 
the translation that happened between the teams: qualitative information had to be turned into quantitative data, not the other way around.

Despite their differing views on the appropriateness and efficacy of commensuration, the ways in which these engineers engaged in this practice add a missing perspective to Li's original conceptualization of the concept. Whereas $\mathrm{Li}$ found that commensuration can depoliticize the decisions undergirding resource extraction, the engineers and applied scientists we came to know engaged in this practice in overtly political ways, with the aim of making resource extraction more responsive to the concerns of the people most affected by it. Even though much scholarship demonstrates how quantification can enact violence through abstraction, it can also open up other possibilities for change in which "counting" empowers "countering" resource extraction (Hebert and Brock 2017). In our case, the engineers counted and made visible (through maps and charts) residents' criticisms of unconventional oil and gas activity, with the aim of changing their coworkers' practices to be more accommodating of local fears and desires.

While ostensibly making resource extraction more responsible, this kind of "conscious capitalism" also ultimately furthers the expansion of industry and its moral authority rather than limiting it (see also Rajak 2011) — a central conundrum navigated by our interviewees. Some took a more instrumental view of the "social license to operate," valuing community acceptance as a strategy for reducing social risk and ultimately making their companies more profitable. Others felt strongly that businesses should be accountable to prevailing local desires, even if it meant sacrificing profitability, for example, by placing some locations with special social or environmental significance off limits for development. Yet those who advocated for a more profound reimagining of relationships among corporations and communities frequently found that they had to justify the importance of good community relations to their coworkers and managers by appealing to the business case for corporate social responsibility--that "doing the right thing" ultimately enhances profitability—as social scientists have found more broadly in the mining industry (Davis and Franks 2014, Kemp and Owen 2013).

Despite the stronghold of the profit motive for responsible practice, our research sheds light on a crucial transformation in engineering practice that opens up possibilities to reimagine relationships among the mining and energy industries and the people affected by them. In companies like the ones employing Aaron, Ryan, Matt, and Nicki, community conflicts have prompted a redefinition of what it means to engineer: being able to see, analyze and engage the surface and subsurface simultaneously, as two interconnected and mutually influencing domains. In their work, these engineers and applied scientists sought to make the consequences of extraction for communities visible to and understandable by their coworkers so that these concerns could be addressed in the production process itself. These activities constitute a potentially more transformative practice of corporate social responsibility: going beyond glossy public relations materials and employee volunteering activities to redefine the role of engineers and engineering to include being responsive to the interests, concerns, and desires of the people affected by their work. 


\section{Acknowledgements}

The authors gratefully acknowledge each of the engineers and applied scientists who made the research possible, as well as the reviewers and editors who provided generative feedback on the article. The research was funded by the National Science Foundation Award 1632651 through the Division of Social and Economic Sciences and the Cultivating Cultures for Ethical STEM program. Any opinions, findings, and conclusions or recommendations expressed in this material are those of the authors and do not necessarily reflect the views of the National Science Foundation.

\section{Author Biography}

Jessica M. Smith is an anthropologist and Associate Professor in the Engineering, Design \& Society Division at the Colorado School of Mines. Her research focuses around the mining and energy industries, with particular emphasis in corporate social responsibility, engineers and engineering education, labor, and gender. She is the author of Mining Coal and Undermining Gender: Rhythms of Work and Family in the American West (Rutgers University Press, 2014), which was funded by the National Endowment for the Humanities and the National Science Foundation.

\section{Author Biography}

Nicole M. Smith is an anthropologist and Assistant Professor in the Mining Engineering Department at the Colorado School of Mines. Her current research focuses on artisanal and small-scale mining; mining, sustainability, and social responsibility; and engineering education.

\section{References}

Appel, Hannah, Arthur Mason, and Michael Watts, eds. 2015. Subterranean Estates: Life Worlds of Oil and Gas. 1 edition. Ithaca London: Cornell University Press.

Appel, Hannah. 2012. "Offshore Work: Oil, Modularity, and the How of Capitalism in Equatorial Guinea." American Ethnologist 39 (4): 692-709.

Bakker, Karen, and Gavin Bridge. 2006. "Material Worlds? Resource Geographies and the 'Matter of Nature."” Progress in Human Geography 30 (1): 5-27.

Barnes, Jessica. 2016. “Uncertainty in the Signal: Modelling Egypt's Water Futures." Journal of the Royal Anthropological Institute 22 (S1): 46-66.

Bowker, Geoffrey. 1994. Science on the Run: Information Management and Industrial Geophysics at Schlumberger, 1920-1940. Cambridge: MIT Press.

Cech, Erin A. 2013. "The (Mis)Framing of Social Justice: Why Meritocracy and Depoliticization Hinder Engineers' Ability to Think About Social Injustices," in Engineering Education for Social Justice: Critical Explorations and Opportunities, edited by Juan Lucena. New York: Springer. Pp. 67-84. 
Davis, Rachel, and David Franks. 2014. Costs of Company-Community Conflict in the Extractive Sector. Corporate Social Responsibility Initiative Report (John F. Kennedy School of Government, Harvard University, Cambridge, MA). Available online: http: / / www.hks.harvard.edu/mrcbg/CSRI/ research/Costs\%20of\%20Conflict_Davis\%20\%20Franks.pdf.

Downey, Gary Lee. 2009. "What is engineering studies for? Dominant practices and scalable scholarship." Engineering Studies 1(1): 55-76.

Downey, Gary Lee, \& Lucena, Juan Carlos 2005. “National identities in multinational worlds: engineers and 'engineering cultures.'” International Journal of Continuing Engineering Education and Life Long Learning 15(3-6): 252-260.

Downey, Gary Lee, Lucena, Juan Carlos, \& Mitcham, Carl. 2007. “Engineering Ethics and Identity: Emerging Initiatives in Comparative Perspective." Science and Engineering Ethics 13(4): 463487.

Ferguson, James. 1994. The Anti-Politics Machine: Development, Depoliticization, and Bureaucratic Power in Lesotho. Minneapolis: University of Minnesota Press.

Ferry, Elizabeth Emma, and Mandana E. Limbert. 2008. Timely Assets: The Politics of Resources and Their Temporalities. Santa Fe: School for Advanced Research Press.

Hébert, Karen \& Samara Brock. 2017. "Counting and Counter-mapping: Contests over the Making of a Mining District in Bristol Bay, Alaska." Science as Culture 26(1): 56-87.

Hughes, David McDermott. 2017. Energy without Conscience: Oil, Climate Change, and Complicity. Durham: Duke University Press Books.

Jalbert, Kirk, Anna Willow, David Casagrande \& Stephanie Paladino. 2017. ExtrACTION: Impacts, Engagements, and Alternative Futures. New York: Routledge.

Jalbert, Kirk, \& Kinchy, Abby. 2016. "Sense and Influence: Environmental Monitoring Tools and the Power of Citizen Science." Journal of Environmental Policy \& Planning 18(3): 379-397.

Kemp, Deanna \& John Owen. 2013. Community relations and mining: Core to business but not "core business." Resources Policy, 38(4), 523-531.

Kinchy, Abby. 2017. "Citizen Science and Democracy: Participatory Water Monitoring in the Marcellus Shale Fracking Boom." Science as Culture 26(1): 88-110.

Kirsch, Stuart. 2014. Mining Capitalism: The Relationship between Corporations and Their Critics. Berkeley: University of California Press.

----. 2006. Reverse Anthropology: Indigenous Analysis of Social and Environmental Relations in New Guinea. Stanford: Stanford University Press.

Kneas, David. 2016. "Subsoil abundance and surface absence: A junior mining company and its performance of prognosis in northwestern Ecuador." Journal of the Royal Anthropological Institute 22(S1): 67-86.

-----. Emergence \& Aftermath: The (Un)becoming of Resources and Identities in Northwestern Ecuador. Unpublished manuscript.

Layton, Edwin T., Jr. 1986. The Revolt of the Engineers: Social Responsibility and the American Engineering Profession. Baltimore, Md: The Johns Hopkins University Press. 
Li, Fabiana. 2011. "Engineering Responsibility: Environmental Mitigation and the Limits of Commensuration in a Chilean Mining Project." Focaal 60: 61-73.

—_ 2015. Unearthing Conflict: Corporate Mining, Activism, and Expertise in Peru. Durham: Duke University Press.

Li, Tania Murray. 2007. The Will to Improve: Governmentality, Development, and the Practice of Politics. Durham: Duke University Press.

Lucena, Juan. 2009. "Imagining nation, envisioning progress: emperor, agricultural elites, and imperial ministers in search of engineers in 19th century Brazil." Engineering Studies 1(3): 191-216.

Lucena, Juan. 2007. "De Criollos a Mexicanos: Engineers' Identity and the Construction of Mexico." History and Technology 23(3): 275-288.

Mathews, Andrew S., and Jessica Barnes. 2016. "Prognosis: Visions of Environmental Futures." Journal of the Royal Anthropological Institute 22 (S1): 9-26.

McNeil, Bryan T. 2011. Combating Mountaintop Removal: New Directions in the Fight against Big Coal. Urbana: University of Illinois Press.

Nash, June. 1979. We Eat the Mines and the Mines Eat Us: Dependency and Exploitation in Bolivian Tin Mines. New York: Columbia University Press.

Noble, David F. 1979. America by Design: Science, Technology, and the Rise of Corporate Capitalism. Oxford: Oxford University Press.

O'Reilly, Jessica. 2016. "Sensing the Ice: Field Science, Models, and Expert Intimacy with Knowledge." Journal of the Royal Anthropological Institute 22 (S1): 27-45.

Ottinger, Gwen. 2013. Refining Expertise How Responsible Engineers Subvert Environmental Justice Challenges. New York: New York University Press.

Powdermaker, Hortense. 1962. Copper Town. Changing Africa the Human Situation on the Rhodesian Copperbelt. New York: Harper \& Row.

Rajak, Dinah. 2011. In Good Company: An Anatomy of Corporate Social Responsibility. Palo Alto: Stanford University Press.

Richardson, Tanya, and Gisa Weszkalnys. 2014. "Introduction: Resource Materialities." Anthropological Quarterly 87 (1): 5-30.

Rolston, Jessica Smith. 2013. "The Politics of Pits and the Materiality of Mine Labor: Making Natural Resources in the American West." American Anthropologist 115 (4): 582-94.

Rosaldo, Rosaldo. 1988. "Ideology, Place, and People without Culture." Cultural Anthropology 3(1): $77-87$.

Sawyer, Suzana. 2004. Crude Chronicles: Indigenous Politics, Multinational Oil, and Neoliberalism in Ecuador. Durham: Duke University Press.

Welker, Marina. 2014. Enacting the Corporation: An American Mining Firm in Post-Authoritarian Indonesia. 1 edition. Berkeley: University of California Press.

----. 2009. "'Corporate Security Begins in the Community': Mining, the Corporate Social Responsibility Industry, and Environmental Advocacy in Indonesia." Cultural Anthropology 24 (1): 142-79. 
Willow, Anna J., Rebecca Zak, Danielle Vilaplana, and David Sheeley. 2014. "The Contested Landscape of Unconventional Energy Development: A Report from Ohio's Shale Gas Country." Journal of Environmental Studies and Sciences 4 (1): 56-64.

Wisnioski, Matthew. 2012. Engineers for Change: Competing Visions of Technology in 1960s America. Cambridge: The MIT Press. 